\title{
AC 2008-1419: KANSAS STATE UNIVERSITY'S ELITE SCHOLARSHIP PROGRAM:ENHANCING LIVES THROUGH TECHNOLOGY AND ENGINEERING
}

\section{Raju Dandu, Kansas State University at Salina}

Raju S. Dandu is the program coordinator and professor of Mechanical Engineering Technology at Kansas State University at Salina. He teaches courses in CNC Machine Processes, Material Strength and Testing, Advanced CAD/CAM, Industrial Instrumentation and Controls, and Automated Manufacturing Systems II. He is active in offering workforce training in reliability centered maintenance, CE certification, process instrumentation and PLCs. His areas of interest are: Product risk analysis, Reliability Centered Maintenance, Energy Efficient Lighting, $\mathrm{CAD} / \mathrm{CAM}$, and Industrial Automation. He is a member of ASEE, ASME, SAE, and SME.

\section{John DeLeon, Kansas State University at Salina}

Dr. De Leon is Professor and Head of Engineering Technology at K-State at Salina. He worked 10 years in industry prior to joining academia where he served 11 years as a faculty member teaching in areas of computer aided design, quality control, industrial ecology and industrial safety. He has published several manuscripts on subject matter related to these curricula. His scholarly pursuits include securing extramural funding for assisting traditionally underrepresented students in engineering complete their education. 


\title{
Kansas State University's ELITE Scholarship Program: Enhancing Lives through Technology and Engineering
}

\begin{abstract}
Kansas State University's Engineering Technology programs are receiving far more employer requests for graduating students than students available to fill the need. This is not merely a local trend. The National Academy of Engineering and National Research Council ${ }^{2}$ confirms that domestic supply of qualified workers is not keeping up with the skill demands in fields that require strong backgrounds in science, technology, engineering and mathematics. Made possible by funding from the National Science Foundation, Scholarship-Science, Technology, Engineering and Mathematics grant ${ }^{1}$, Kansas State's Enhancing Lives through Technology and Engineering (ELITE) scholarship program will help ensure the increase of associate and baccalaureate degrees among the academically talented but financially needy students of Kansas. Our proposal fosters a mechanism that will enable qualifying students to secure an Engineering Technology degree from K-State at Salina. By building on current partnerships with high schools and enhancing those with community colleges, the ELITE program will provide a bridge inviting interested students from around the state to submit their applications to become an ELITE scholar. Thus, ELITE scholars will comprise freshmen, transfer or current K-State students.
\end{abstract}

This presentation will provide insight into the structure of the award winning proposal. Furthermore, information related to application demographics and the selection process will be disseminated.

\section{Introduction}

K-State at Salina Engineering Technology Department applied for S-STEM (Scholarships in Science, Technology, Engineering, and Mathematics) grant in 2006 and has been named the recipient of a \$500,000 grant from the National Science Foundation (NSF) for its Enhancing Lives Through Engineering and Technology (ELITE) Program. The NSF program solicitation ${ }^{1}$ states that "S-STEM program provides institutions with funds for student scholarships to encourage and enable academically talented but financially needy students to enter the workforce following completion of an associate, baccalaureate, or graduate degree in fields of science, technology, engineering, or mathematics."

The ELITE scholarship grant program started in fall 2007 and runs through 2011. With this grant the engineering technology department will be able to award 15-25 scholarships annually (up to $\$ 5,000$ per scholarship) for the next four academic years for students majoring in construction engineering technology, computer systems technology, electronics and computer engineering technology and mechanical engineering technology. The ELITE scholarship grant will facilitate recruitment, retention, graduation, and placement of diverse group academically talented but financially needy students in engineering technology fields in the high technology industries in Kansas. In fall 07, 27 scholarships were awarded in the amount of \$1800/semester. Administering the grant in its first year has been rewarding and challenging. This paper will provide insight into the structure of the award winning proposal and information related to application demographics and the selection process. 


\section{Grant Proposal Structure}

Successful grant proposal needs an excellent teamwork, leadership, and administrative support of an academic institution. The grant writing team has been mindful of specific instructions, limitations, and requirements of S-STEM proposal.

\section{ELITE Proposal}

Kansas State's Enhancing Lives through Technology and Engineering (ELITE) scholarship program will help ensure the increase of associate and baccalaureate degrees among the academically talented but financially needy students of Kansas. Our proposal fosters a mechanism that will enable qualifying students to secure an Engineering Technology degree from K-State at Salina. Through efforts of a multi-discipline team of faculty and campus-wide student support service specialists, ELITE scholars will be recruited, retained, mentored, graduated and ultimately placed in the workforce. By building on current partnerships with high schools and enhancing those with community colleges, the ELITE program will provide a bridge inviting interested students from around the state to submit their applications to become an ELITE scholar. Thus, ELITE scholars will comprise freshmen, transfer or current K-State students.

Specifically, the ELITE program will provide financial assistance to a cluster of 15-25 students over a period of four years beginning fall 2007. Budget for the program is estimated at $\$ 500,000$ with $\$ 28,000$ earmarked for program administration and $\$ 32,000$ for student support services. Included in the total are initial start-up funds that will be utilized to carry out planning for the ELITE project and to put administrative and support structures in place. The S-STEM grant allows a maximum award of $\$ 500,000$ in total or $\$ 125,000$ per year for up to four years, with an optional initial period of up to one year for planning. The maximum scholarship amount is up to $\$ 10,000$ per student per year.

Funding sought for this initiative will yield the following objectives:

1. To increase the number of traditionally underrepresented students (low-income, rural, first generation, ethnic and gender minorities) in STEM areas.

2. To provide a pathway for PLTW (Project Lead the Way) high school graduates to complete an associate or baccalaureate engineering technology degree.

3. To increase the number of community college transfers awarded baccalaureate degrees in engineering technology.

4. To provide leadership and cultural experiences to ELITE scholars.

5. To facilitate scholar exposure to real life experiences of potential careers with industry internships.

\section{Meeting the S-STEM Program Goals}

The ELITE scholarship program builds upon prevailing departmental recruitment, retention, and job placement philosophies and strategies. Funding through this grant opportunity will lead to 
enhancements and innovations to assist in the realization of S-STEM goals. The S-STEM program states ${ }^{1}$ that the participating institutions are expected to support the goals of the SSTEM program including:

- Improved educational opportunities for students;

- Increased retention of students to degree achievement;

- Improved student support programs at institutions of higher education;

- Increased numbers of well educated and skilled employees in technical areas of national need.

The following narrative outlines action items of ELITE scholarship proposal to satisfy each of the four goals.

Goal 1. Improved educational opportunities for students.

- Articulate seamless transfer of community college credits

○ Link with targeted high schools offering PLTW programs

Goal 2. Increased retention of students to degree achievement.

- Promote the ELITE Scholarship project, especially to underrepresented groups.

- Identify and maintain a pool of eligible students to pursue careers in engineering technology.

Goal 3. Improved student support programs at institutions of higher education.

- Assist scholarship recipients with academic advising, career planning, and student support services.

- Facilitate mentoring and engage students in personal and professional development activities.

Goal 4. Increased numbers of well educated and skilled employees in technical areas of national need.

- Assist students with preparation for career planning and placement through career services office.

- Engage and connect students with employers through professional associations, career fairs, and industry internships.

\section{Activities on Which the Current Project Builds}

The ELITE Program builds on the following activities already in place in the College of Technology and Aviation at K-State at Salina:

- Articulation agreements newly signed or in progress with all Community Colleges across the State of Kansas.

- Introductory collaboration with Kansas PLTW school programs to introduce these students to Engineering Technology opportunities at K-State at Salina.

- A strong set of student services and support programs available within the College.

- Close interaction with industry employers and internships already being promoted through the College's own Career Services, enabling ease of placement of ELITE scholars into applicable internships. 
Further, the student services and support programs available on campus to support ELITE program goals include:

- Admission guidance services

- Academic advising rated among the highest in the University (Fall 2004 Advising Survey)

- Upward Bound program

- Placement testing for all students in math and English

- Academic Achievement Center (including peer tutoring and computer-aided math tutorial and test-taking software systems)

- Disability services

- Student life programs

- Career Services

- Student organizations and clubs

- Multi-cultural activities

\section{ELITE Educational Experiences}

The following educational experiences will enrich and broaden the perspectives of ELITE scholars. The following activities, while be open to various other student populations on an optional basis but will be mandatory for ELITE students:

\section{Enhanced Capstone Experiences}

All Engineering Technology students are required to take a senior project course for their capstone experience during the fall semester of their senior year. This course focuses on the principles and design methodology required to solve a significant design problem in a team context. The project encompasses determining customer requirements, exploring and choosing design alternatives, scheduling, and project management. Significant milestones are the project's conceptual, preliminary, and critical design reviews, which require written and oral presentations. Often these projects are supported by local industry and they involve real world design problems. An augmented capstone experience will be provided for ELITE scholars. ELITE scholars are required to consult and provide progress reports to faculty advisors in their respective degree program areas.

\section{Internship Education}

An internship course is currently optional for engineering technology students. However, ELITE scholars will be mandated to take three credits of internship learning. This experience will develop students' interpersonal and professional skills and will likewise give them an advantage in terms of future job placement. Two of K-State at Salina's industrial partners has pledged to provide scholars with internship opportunities.

\section{Professional Membership}

In order to promote professional development all ELITE students are required to join one of the on-campus student clubs and or professional organizations such as Society of Manufacturing Engineers (SME), the Institute of Electrical and Electronic Engineers (IEEE), or Association of 
Computing Machinery (ACM). These student clubs engage regularly in such activities as industrial plant tours and guest speaker presentations.

Multicultural Programs

K-State at Salina provides a healthy dose of multicultural programs on campus both through student organizations and through the Multicultural Connection Committee. ELITE scholars are required to attend and/or participate in certain events selected by their ELITE advisors.

\section{Freshmen Seminar}

The Engineering Technology department is restructured freshmen seminar course to include the following modules: (a) adjusting to university life, (b) understanding the purpose of a university education, (c) skills that promote academic success and (d) diversity: issues and concepts. Consequently, freshmen and transfer ELITE scholars will be required to participate in the course.

\section{Student Selection Process and Criteria}

Application and screening materials are utilized for the purpose of identifying the academically proficient but economically disadvantaged student. Students are able to apply for a scholarship under one of the three following classifications: incoming freshman, transfer student or current K-State at Salina student. Family economics, first generation college status, primary language spoken at home, GPA, ACT/SAT scores, grades in foundation high school mathematics and science courses, leadership, work history, motivation as expressed in an essay, and faculty recommendations are taken into consideration.

A scholarship committee comprising seven members will select candidates based on resource availability and student eligibility. Only declared Engineering Technology majors will be eligible for an ELITE award. Financial assistance will cease once the student completes the baccalaureate degree or is deemed academically or financially ineligible. Students will be required to sign an agreement that clarifies eligibility requirements and other stipulations requisite to their involvement in the program. After the $20^{\text {th }}$ day roster of every semester the PI will forward to the Registrar's office a list of certified ELITE scholars. The Registrar's Office will work in tandem with the Financial Aid Office to ensure that these students receive tuition credit.

\section{Maintenance of Records and Reporting Responsibilities}

Each S-STEM goal is identified along with purposefully crafted action items geared for goal fruition and outcome measures are used to assess and evaluate project success. Data collection procedures resulted in the creation and maintenance of a database inclusive of the standard demographic information, overall grade information, and participation in ELITE activities. This tracking system will be updated by semester and longitudinally for all semesters.

Annual reports are submitted via the web through FastLane. In FastLane five categories in which information should be submitted: Participants, Activities and Findings, Publications and Products, Contributions, and Special Requirements. 


\section{Challenges in Administering the Grant}

There are many challenges the project director has to face in administering the grant such as monitoring academic progress, gathering required student statistics, and organizing events. It is recommended that most of the project management plan, scholarship advertisement, student recruitment plan, project timeline, and scholarship applicant screening process, verifying financial aid information, and notifying students should be well thought in advance.

\section{Conclusion}

The ELITE Program is attempting to increase both bachelor and associate level degree graduates in engineering technology. This grant is a five year grant (one year planning and four years offering scholarships) which has gotten off to a good start in the first year. The overall impact has yet to be seen. So far the impact on total enrollment is minimal. The promotion materials about the ELITE scholarship brought more awareness about engineering technology pathways at high schools, technical colleges, community colleges.

\section{Bibliography}

1. NSF Scholarships in Science, Technology, Engineering, and Mathematics (S-STEM) from the World Wide Web: http://www.nsf.gov/pubs/2006/nsf06527/nsf06527.htm

2. NAE/NRC (National Academy of Engineering and National Research Council). 2005. Enhancing the Community College Pathway to Engineering Careers. Washington, DC: The National Academies Press. 